ARTICLE

\title{
Fine pore engineering in a series of isoreticular metal-organic frameworks for efficient $\mathrm{C}_{2} \mathrm{H}_{2} / \mathrm{CO}_{2}$ separation
}

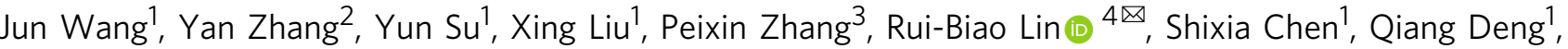 \\ Zheling Zeng ${ }^{1}$, Shuguang Deng ${ }^{5 凶} \&$ Banglin Chen (i) ${ }^{6 凶}$
}

The separation of $\mathrm{C}_{2} \mathrm{H}_{2} / \mathrm{CO}_{2}$ is not only industrially important for acetylene purification but also scientifically challenging owing to their high similarities in physical properties and molecular sizes. Ultramicroporous metal-organic frameworks (MOFs) can exhibit a pore confinement effect to differentiate gas molecules of similar size. Herein, we report the finetuning of pore sizes in sub-nanometer scale on a series of isoreticular MOFs that can realize highly efficient $\mathrm{C}_{2} \mathrm{H}_{2} / \mathrm{CO}_{2}$ separation. The subtle structural differences lead to remarkable adsorption performances enhancement. Among four MOF analogs, by integrating appropriate pore size and specific binding sites, $\left[\mathrm{Cu}(\mathrm{dps})_{2}\left(\mathrm{SiF}_{6}\right)\right]$ (SIFSIX-dps-Cu, SIFSIX $=\mathrm{SiF}_{6}{ }^{2-}, \mathrm{dps}=$ 4.4'-dipyridylsulfide, also termed as NCU-100) exhibits the highest $\mathrm{C}_{2} \mathrm{H}_{2}$ uptake capacity and $\mathrm{C}_{2} \mathrm{H}_{2} / \mathrm{CO}_{2}$ selectivity. At room temperature, the pore space of SIFSIX-dps-Cu significantly inhibits $\mathrm{CO}_{2}$ molecules but takes up a large amount of $\mathrm{C}_{2} \mathrm{H}_{2}\left(4.57 \mathrm{mmol} \mathrm{g}^{-1}\right)$, resulting in a high IAST selectivity of 1787 for $\mathrm{C}_{2} \mathrm{H}_{2} / \mathrm{CO}_{2}$ separation. The multiple host-guest interactions for $\mathrm{C}_{2} \mathrm{H}_{2}$ in both inter- and intralayer cavities are further revealed by dispersion-corrected density functional theory and grand canonical Monte Carlo simulations. Dynamic breakthrough experiments show a clean $\mathrm{C}_{2} \mathrm{H}_{2} / \mathrm{CO}_{2}$ separation with a high $\mathrm{C}_{2} \mathrm{H}_{2}$ working capacity of $2.48 \mathrm{mmol} \mathrm{g}^{-1}$.

\footnotetext{
${ }^{1}$ School of Resource, Environmental and Chemical Engineering, Nanchang University, Nanchang 330031 Jiangxi, PR China. ${ }^{2}$ Jiangxi University of Chinese Medicine, Nanchang 330031 Jiangxi, PR China. ${ }^{3}$ Key Laboratory of Biomass Chemical Engineering of Ministry of Education, College of Chemical and Biological Engineering, Zhejiang University, Hangzhou 310027 Zhejiang, PR China. ${ }^{4}$ MOE Key Laboratory of Bioinorganic and Synthetic Chemistry, School of Chemistry, Sun Yat-Sen University, Guangzhou 510006 Guangdong, China. ${ }^{5}$ School for Engineering of Matter, Transport and Energy, Arizona State University, 551 E. Tyler Mall, Tempe, AZ 85287, USA. ${ }^{6}$ Department of Chemistry, University of Texas at San Antonio, One UTSA Circle, San Antonio, TX 78249-0698, USA.『email: linruibiao@mail.sysu.edu.cn; shuguang.deng@asu.edu; banglin.chen@utsa.edu
} 
A cetylene $\left(\mathrm{C}_{2} \mathrm{H}_{2}\right)$ is a major raw feedstock for the production of various essential polymers and chemicals ${ }^{1-3}$. In industry, $\mathrm{C}_{2} \mathrm{H}_{2}$ is produced by partial $\mathrm{CH}_{4}$ combustion and thermal hydrocarbon cracking, in which carbon dioxide $\left(\mathrm{CO}_{2}\right)$ is a worth-noting impurity that can show great impact upon the subsequent industrial processes ${ }^{4,5}$. Currently, energy-intensive solvent extraction and cryogenic distillations are employed to separate $\mathrm{C}_{2} \mathrm{H}_{2} / \mathrm{CO}_{2}$ mixtures ${ }^{6}$. Due to the close boiling points $(189.3 \mathrm{~K}$ for $\mathrm{C}_{2} \mathrm{H}_{2} ; 194.7 \mathrm{~K}$ for $\mathrm{CO}_{2}$ ), these approaches suffer from low energy efficiency and are environmentally unfriendly ${ }^{7-9}$. Therefore, it is urgent to develop an energy-efficient approach to realize the challenging $\mathrm{C}_{2} \mathrm{H}_{2} / \mathrm{CO}_{2}$ separation. Adsorption-based gas separation using porous materials represents a promising alternative technology ${ }^{10-12}$. Nevertheless, $\mathrm{C}_{2} \mathrm{H}_{2}$ and $\mathrm{CO}_{2}$ gas molecules show identical molecular shapes (dimensions: $3.32 \times 3.34 \times 5.7 \AA^{3}$ for $\mathrm{C}_{2} \mathrm{H}_{2} ; 3.18 \times 3.33 \times 5.36 \AA^{3}$ for $\left.\mathrm{CO}_{2}\right)$ and kinetic diameters $(3.3 \AA$, Supplementary Fig. 1), making it very challenging to develop highperformance adsorbents for $\mathrm{C}_{2} \mathrm{H}_{2} / \mathrm{CO}_{2}$ separation through physisorption $^{13-15}$.

Metal-organic frameworks (MOFs) are well-known for their readily tunable pore sizes/shapes and internal surface modification ${ }^{16-19}$. By virtue of the isoreticular principle and building blocks approach in MOF chemistry, the pore adjustment of porous materials has been performed in a more predictable and more precise way ${ }^{20-24}$. By substituting organic linkers and/or metal nodes, the pore space in MOFs can integrate shape matching and specific binding toward targeted gas molecules ${ }^{25,26}$. SIFSIX-type MOFs featuring anionic $\mathrm{MF}_{6}{ }^{2-}$ groups $(\mathrm{M}=\mathrm{Si}, \mathrm{Ti}$, $\mathrm{Ge}$, etc.) have been demonstrated as efficient adsorbents for many separations, mainly attributed to their high-density fluorinated sites and high-sieving pore ${ }^{27}$. The fluoride atoms can serve as hydrogen bonding acceptors forming strong interactions with $\mathrm{C}_{2} \mathrm{H}_{2}{ }^{28}$. On the other hand, the length of dipyridine linkers that defines the pore aperture is variable upon substitution, thus tuning the aperture size of one-dimensional (1D) pore channels in these MOF materials ${ }^{29}$. This uniqueness makes SIFSIX-type MOFs a prominent platform with several progresses for separation such as $\mathrm{C}_{2} \mathrm{H}_{2} / \mathrm{C}_{2} \mathrm{H}_{4}{ }^{30}, \mathrm{C}_{3} \mathrm{H}_{4} / \mathrm{C}_{3} \mathrm{H}_{6}{ }^{31}, \quad \mathrm{C} 4$ isomers separation $^{32}$, and $\mathrm{CO}_{2}$ capture $^{33}$. Among these SIFSIX-type materials, a flexible MOF [ $\left.\mathrm{Zn}(\mathrm{dps})_{2}\left(\mathrm{SiF}_{6}\right)\right]$ (UTSA-300-Zn, SIFSIX-dps-Zn) was able to completely differentiate $\mathrm{C}_{2} \mathrm{H}_{2}$ and $\mathrm{CO}_{2}$ gas molecules. However, flexible MOFs usually show negligible gas uptake before gate-opening, which might lead to capture leakage when applied to the breakthrough separation of gas mixture ${ }^{34-38}$. In this context, flexible-robust MOFs with permanent small pores as well as specific binding sites have been employed to selective take up targeted gas molecules, whereas minimizing the co-adsorption of counterpart gases by tuning the gate-opening pressure, which has been demonstrated by $\left[\mathrm{Cu}(\mathrm{dps})_{2}\left(\mathrm{SiF}_{6}\right)\right]$ (SIFSIX-dps-Cu) for size-exclusive adsorption of $\mathrm{C}_{2} \mathrm{H}_{2}$ from $\mathrm{C}_{2} \mathrm{H}_{4}{ }^{39}$. To achieve simultaneously high capacity and separation selectivity for more challenging $\mathrm{C}_{2} \mathrm{H}_{2} / \mathrm{CO}_{2}$ separation, a systematical study on fine-tuning of pore structure in prototypal $\left[\mathrm{Zn}(\mathrm{dps})_{2}\left(\mathrm{SiF}_{6}\right)\right]$ would be a rational approach.

Herein, we demonstrate precise control over pore structure through altering anionic linkers and metal nodes in $\left[\mathrm{Zn}(\mathrm{dps})_{2}\left(\mathrm{SiF}_{6}\right)\right]$ to increase both $\mathrm{C}_{2} \mathrm{H}_{2}$ uptake capacity and $\mathrm{C}_{2} \mathrm{H}_{2} / \mathrm{CO}_{2}$ selectivity. Combining different anionic linkers, three flexible-robust MOFs with precise modulation of pore cavity sizes in a sub-nanometer scale have been utilized for the challenging $\mathrm{C}_{2} \mathrm{H}_{2} / \mathrm{CO}_{2}$ separation. By integrating suitable pore size and fluorinated binding sites, the exclusive $\mathrm{C}_{2} \mathrm{H}_{2}$ sorption behavior was retained in $\left[\mathrm{Cu}(\mathrm{dps})_{2}\left(\mathrm{SiF}_{6}\right)\right]$ (SIFSIX-dps-Cu, SIFSIX $=$ $\mathrm{SiF}_{6}{ }^{2-}, \mathrm{dps}=4.4^{\prime}$-dipyridylsulfide, also termed as NCU-100) with a $\mathrm{C}_{2} \mathrm{H}_{2}$ uptake of $4.57 \mathrm{mmol} \mathrm{g}^{-1}$ and negligible $\mathrm{CO}_{2}$ uptake, resulting in a high IAST selectivity of 1787 for $\mathrm{C}_{2} \mathrm{H}_{2} / \mathrm{CO}_{2}$ separation. The highly efficient $\mathrm{C}_{2} \mathrm{H}_{2} / \mathrm{CO}_{2}$ separation in $\left[\mathrm{Cu}(\mathrm{dps})_{2}\left(\mathrm{SiF}_{6}\right)\right]$ has been validated by molecular modeling studies and dynamic breakthrough experiments.

\section{Results}

Synthesis and characterization. A series of SIFSIX-dps-Zn variants, SIFSIX-dps-Cu (SIFSIX $=\mathrm{SiF}_{6}{ }^{2-}$, $\mathrm{dps}=4.4^{\prime}$-dipyridylsulfide, termed as NCU-100), GeFSIX-dps-Cu (GeFSIX $\left.=\mathrm{GeF}_{6}{ }^{2-}\right)$, and NbOFFIVE-dps-Cu (NbOFFIVE $\left.=\mathrm{NbOF}_{5}{ }^{2-}\right)$ were successfully prepared through solution reactions (Fig. 1a, see Supplementary Information for synthetic and crystallographic details). Crystal structures of the as-synthesized MOFs were determined by singlecrystal X-ray diffraction studies, and the phase purities of assynthesized and activated samples were confirmed by the XRD measurements (Supplementary Figs. 2-4 and Supplementary Table 1). Each $\mathrm{Cu}(\mathrm{II})$ atom connects four independent pyridinyl rings of dps ligands and affords $1 \mathrm{D}$ chains, generating the intralayer cavity (Site I) with the size of $3.0 \times 3.2 \AA^{2}, 2.5 \times 3.1 \AA^{2}$, and $2.3 \times 3.1 \AA^{2}$ on NbOFFIVE-dps-Cu, GeFSIX-Cu-dps-Cu, and SIFSIX-dps-Cu, respectively (Fig. $1 \mathrm{~b}$ and Supplementary Fig. 5a). These apertures are larger than those of the intralayer channels $\left(2.2 \times 3.1 \AA^{2}\right)$ in UTSA-300 (SIFSIX-dps-Zn). The chains are further bridged by different anion pillars in the perpendicular direction at $\mathrm{Cu}$ (II) sites to form 2D MOF layers containing $1 \mathrm{D}$ wavy interlayer channels. The 2D MOF layer planes stack with each other via multiple hydrogen bonds between guest water molecules and $\mathrm{F}$ atoms of anion pillars, rendering the structural flexibility and dynamics (Supplementary Fig. 6). The size of the interlayer cavity (Site II) on NbOFFIVE-dps-Cu, GeFSIX-Cu-dps-Cu, and SIFSIXdps-Cu are $3.2 \times 4.8 \AA^{2}, 2.8 \times 4.8 \AA^{2}$, and $2.9 \times 4.4 \AA^{2}$, respectively (Fig. 1c and Supplementary Fig. 5b). These results illustrate that both interlayer and intralayer cavities can be finely tuned by altering the anion pillars due to different $\mathrm{M}-\mathrm{F}$ distances $(1.69 \AA$ for Si $\cdots F$, $1.75 \AA$ for Ge $\cdots F$, and $1.81 \AA$ for $\mathrm{Nb} \cdots \mathrm{F}$ ).

Although the as-synthesized samples have a similar layered stacking pattern, notable structural transformations are observed after activation, and the activated crystal structures are determined by Rietveld refinements (Fig. 1 and Supplementary Fig. 7 and Supplementary Tables 2-5). In contrast to the $\mathrm{Zn}$ analog UTSA-300 (Site I: $1.3 \times 2.8 \AA^{2}$ vs. $2.3 \times 3.1 \AA^{2}$ for as-synthesized), all $\mathrm{Cu}$-based dynamic layered MOFs displayed slightly expanded intralayer cavity owing to the elongated $\mathrm{Cu}-\mathrm{F}$ bonds $(2.27 \AA)$ than $\mathrm{Zn}-\mathrm{F}$ bond $(2.09 \AA)$. As shown in Fig. 1, the activated NbOFFIVE-dps-Cu showed the largest pore aperture size of $2.2 \times 2.7 \AA^{2}$ at Site I, in contrast to those in GeFSIX-dps-Cu $\left(1.5 \times 3.0 \AA^{2}\right)$ and SIFSIX-dps-Cu $\left(1.4 \times 3.0 \AA^{2}\right)$. The expanded pore spaces are conducive for potential $\mathrm{C}_{2} \mathrm{H}_{2}$ diffusion. Furthermore, the removal of solvent allows the interlayer $\pi-\pi$ stacking of dps ligands, giving closed interlayer cavities (Supplementary Fig. 8). The interlayer distance (S atoms to the $2 \mathrm{D}$ layer center) was measured to be $4.10 \AA$ in SIFSIX-dps-Cu, and followed by GeFSIX-dps-Cu (4.06 ̊̊), UTSA-300 (4.05 $)$, and NbOFFIVE-dps-Cu (3.69 $\AA$ ), leading to varying interlayer pore spaces upon different packing density ${ }^{13,40}$. The changes of powder X-ray diffraction (PXRD) patterns and corresponding structural transformation in the three isoreticular MOFs upon desolvation or $\mathrm{C}_{2} \mathrm{H}_{2}$-loading are the same as the prototypical zinc analogue UTSA-300 (Supplementary Figs. 2-4 and Supplementary Tables $2-5)^{13}$.

Adsorption and separation performances. The permanent porosity of these dynamic layered MOFs is probed by $\mathrm{CO}_{2}$ adsorption isotherms at $195 \mathrm{~K}$, and the Brunauer-Emmett-Teller specific surface area was determined as 358,310 , and $173 \mathrm{~m}^{2} \mathrm{~g}^{-1}$ for SIFSIX-dps-Cu, GeFSIX-dps-Cu, and NbOFFIVE-dps-Cu, 


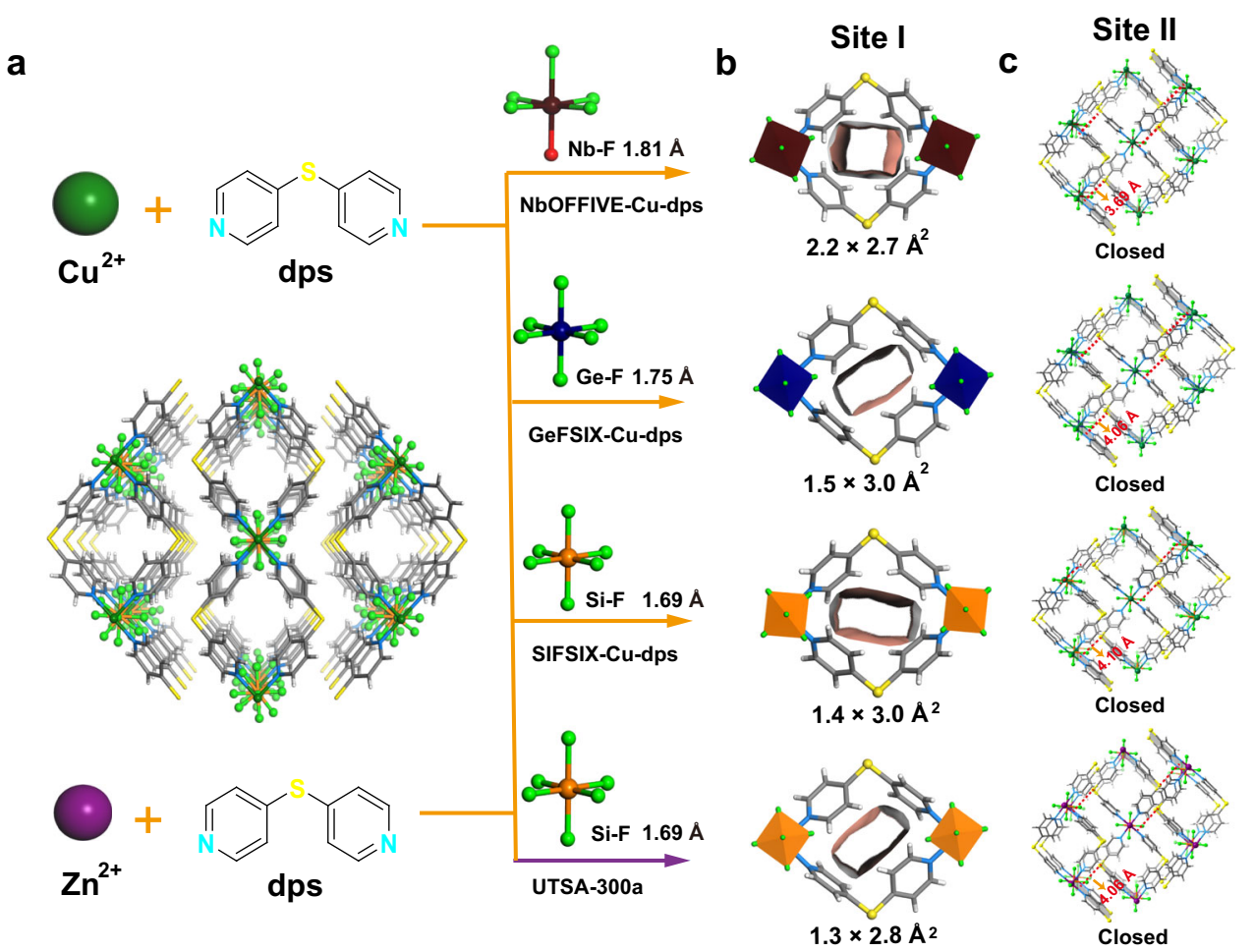

Fig. 1 Crystallographic structures. a Synthesis procedure of three isoreticular MOFs. Views of b Site I and c Site II in activated NbOFFIVE-dps-Cu, GeFSIXdps-Cu, SIFSIX-dps-Cu, and UTSA-300a with varying pore aperture size. Color code: $\mathrm{Cu}$, green; F, light green; S, bright yellow; N, light blue; C, gray; Si, orange; $\mathrm{Ge}$, navy blue; $\mathrm{Nb}$, wine red; and solvent molecules are omitted for clarity.

respectively (Supplementary Figs. 9 and 10). It should be noted that NbOFFIVE-dps-Cu exhibits stepwise adsorption behavior with a smaller pore volume $\left(0.09 \mathrm{~cm}^{3} \mathrm{~g}^{-1}\right.$, at $\left.P / P_{0} \sim 0.25\right)$ before gate-opening as compared to those of SIFSIX-dps-Cu $\left(0.20 \mathrm{~cm}^{3} \mathrm{~g}^{-1}\right)$ and GeFSIX-dps-Cu $\left(0.19 \mathrm{~cm}^{3} \mathrm{~g}^{-1}\right)$, although it shows a potential total pore volume of $0.30 \mathrm{~cm}^{3} \mathrm{~g}^{-1}$. Thermogravimetric analysis revealed that these layered MOFs are stable up to $443 \mathrm{~K}$ (Supplementary Fig. 11). The XRD patterns showed that the activated structures can be restored to the as-synthesized state after being placed in the air for $24 \mathrm{~h}$ (Supplementary Figs. 2-4). Single-component equilibrium adsorption isotherms of $\mathrm{C}_{2} \mathrm{H}_{2}$ and $\mathrm{CO}_{2}$ were collected at 273,298 , and $323 \mathrm{~K}$ (Supplementary Figs. 12-14). The $\mathrm{C}_{2} \mathrm{H}_{2}$ uptake of SIFSIX-dps-Cu, GeFSIX-dps-Cu, and NbOFFIVE-dps-Cu was measured to be $4.57,4.04$, and $1.65 \mathrm{mmol} \mathrm{g}^{-1}$ at $298 \mathrm{~K}$ and $1.0 \mathrm{bar}$, respectively (Fig. 2a). The high $\mathrm{C}_{2} \mathrm{H}_{2}$ uptake of SIFSIX-dps-Cu $\left(4.57 \mathrm{mmol} \mathrm{g}^{-1}\right)$ outperforms many benchmark MOFs, including CPL-1- $\mathrm{NH}_{2}\left(1.84 \mathrm{mmol} \mathrm{g}^{-1}\right)^{41}$, NTU-65 $\left(3.36 \mathrm{mmol} \mathrm{g}^{-1}\right)^{34}$, and JNU-1 $\left(2.1 \mathrm{mmolg}^{-1}\right)^{5}$, see Supplementary Table 6 . The sorption behaviors of these dynamic MOFs are similar to those in relevant literature ${ }^{39,42}$. The three MOF show similar $\mathrm{C}_{2} \mathrm{H}_{2}$ adsorption capacities $\left(\sim 0.85 \mathrm{mmol} \mathrm{g}^{-1}\right)$ at the low-pressure region (Fig. 2b). This gate-opening phenomenon can be attributed by structural dynamics including the rotation of pyridinyl rings upon $\mathrm{C}_{2} \mathrm{H}_{2}$-loading. There are differences on the torsion angle between anion pillar and dps ligand before and after $\mathrm{C}_{2} \mathrm{H}_{2}$ loading in SIFSIX-dps-Cu $\left(7^{\circ}\right)$, GeFSIX-dps- $\mathrm{Cu}\left(6^{\circ}\right)$, and NbOFFIVE-dps- $\mathrm{Cu}\left(1^{\circ}\right)$, all of which are much smaller than that of UTSA-300a $\left(17^{\circ}\right)$ (Supplementary Figs. 15-16), matching well with corresponding static sorption results. The $\mathrm{C}_{2} \mathrm{H}_{2}$ threshold pressure for gate-opening of NbOFFIVE-dps-Cu is around $0.3 \mathrm{bar}$ at $273 \mathrm{~K}$, which was significantly higher than those of $0.06,0.05$, and 0.035 bar for UTSA-300a, GeFSIX-dps-Cu, and SIFSIX-dps-
$\mathrm{Cu}$, respectively (Fig. 2c). The dynamic adsorption behaviors were consistent with the trend of interlayer $\pi-\pi$ stacking distances.

These results demonstrate that the subtle change of dynamic layered MOFs by substituting different pillared anions can greatly impact the $\mathrm{C}_{2} \mathrm{H}_{2}$ adsorption behavior, which would ultimately affect the selectivity of $\mathrm{C}_{2} \mathrm{H}_{2} / \mathrm{CO}_{2}$. At $298 \mathrm{~K}$, NbOFFIVE-dps-Cu showed smooth $\mathrm{CO}_{2}$ adsorption of $1.10 \mathrm{mmol} \mathrm{g}^{-1}$. In contrast, GeFSIX-dps-Cu and SIFSIX-dps-Cu show minor $\mathrm{CO}_{2}$ uptake at low-pressure regions, although the latter shows stepwise $\mathrm{CO}_{2}$ uptake at $273 \mathrm{~K}$ and pressures above $0.7 \mathrm{bar}\left(2.34 \mathrm{mmol} \mathrm{g}^{-1}\right.$ at $1.0 \mathrm{bar}$, Fig. $2 \mathrm{~d}$ ). This might be ascribed to the gate-opening effect in the relatively flexible framework of SIFSIX-dps-Cu upon strong interactions with $\mathrm{CO}_{2}$. To investigate the adsorption phenomena for gas mixture, mixed-components adsorption isotherms of the three isoreticular MOFs for $\mathrm{C}_{2} \mathrm{H}_{2} / \mathrm{CO}_{2}(50 / 50, \mathrm{~mol} / \mathrm{mol})$ have also been collected (Supplementary Fig. 17). Compared with the single component sorption results, their adsorption capacity and threshold pressure are basically not changed, which confirms the preferential adsorption of $\mathrm{C}_{2} \mathrm{H}_{2}$ from $\mathrm{C}_{2} \mathrm{H}_{2} / \mathrm{CO}_{2}$ mixture ${ }^{43}$. Prompted by the dramatic uptake differences, the ideal adsorbed solution theory (IAST) was applied to qualitatively estimate the $\mathrm{C}_{2} \mathrm{H}_{2} / \mathrm{CO}_{2}$ selectivity, while the adsorption isotherms are fitted by the dual-site Langmuir-Freundlich equation with excellent accuracy (Supplementary Figs. 18-29 and Supplementary Table 7). As shown in Fig. 2e and Supplementary Fig. 30, the calculated equimolar $\mathrm{C}_{2} \mathrm{H}_{2} / \mathrm{CO}_{2}$ selectivity of NbOFFIVE-dps$\mathrm{Cu}, \mathrm{GeFSIX}-\mathrm{dps}-\mathrm{Cu}$, and SIFSIX-dps-Cu at $298 \mathrm{~K}$ and 1.0 bar are 9,172 , and 1787 , respectively. In particular, the selectivity of SIFSIX-dps-Cu is higher than that of UTSA-300a (743) and much higher than other benchmark MOFs (Supplementary Table 6), such as CPL-1- $\mathrm{NH}_{2}(119)^{41}$, ATC-Cu (53.6) $)^{9}$, TIFSIX-2-Cu-i $(6.5)^{44}$, UTSA-74a $(9)^{45}$, and UTSA-222a (2) ${ }^{46}$. Compared with those of adsorbents with high $\mathrm{C}_{2} \mathrm{H}_{2}$ adsorption capacities such as 
a

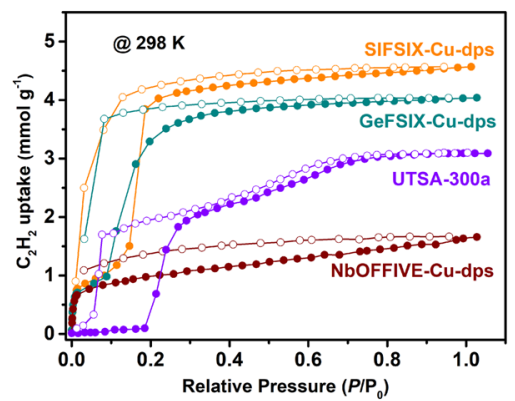

d

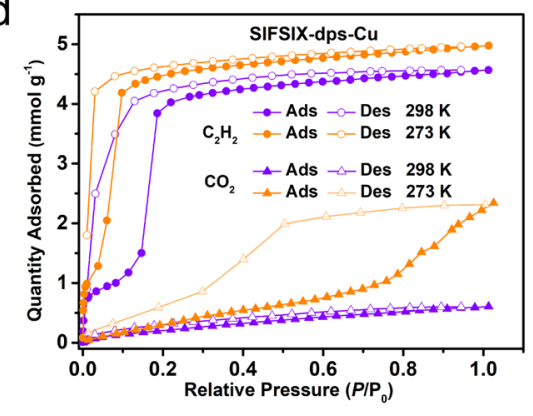

b

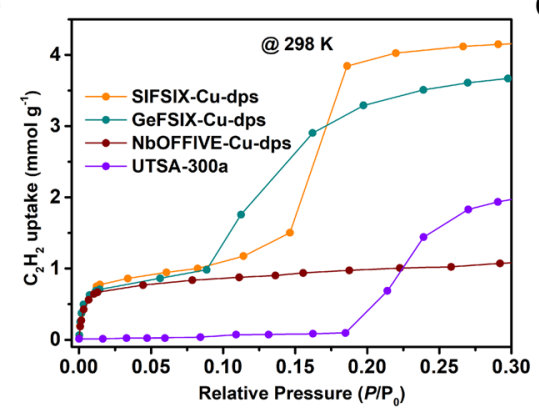

e

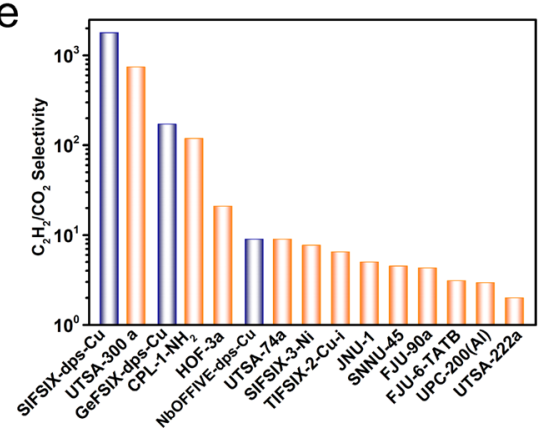

C

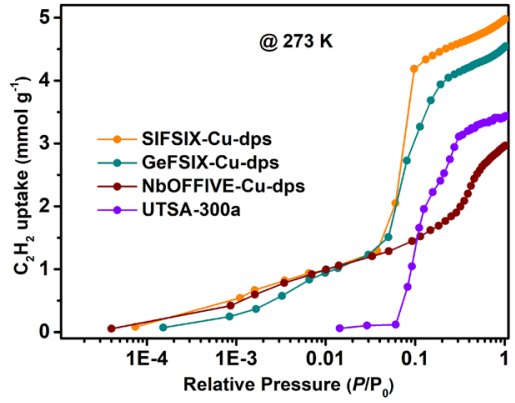

f

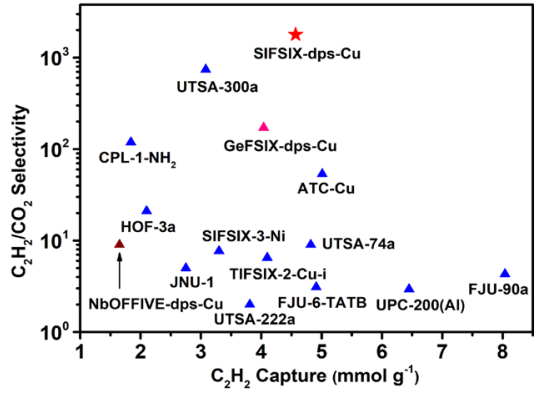

Fig. $2 \mathbf{C}_{\mathbf{2}} \mathbf{H}_{\mathbf{2}}$ and $\mathbf{C O}_{\mathbf{2}}$ sorption in four isoreticular MOFs. The $\mathrm{C}_{2} \mathrm{H}_{2}$ sorption isotherms at $\mathbf{a} 0-1.0$ bar and $\mathbf{b} 0-0.3$ bar under $298 \mathrm{~K}$. c The $\mathrm{C}_{2} \mathrm{H}_{2}$ sorption isotherms at logarithmic 0.01-1.0 bar of SIFSIX-dps-Cu, GeFSIX-dps-Cu, NbOFFIVE-dps-Cu, and UTSA-300a at $273 \mathrm{~K}$. d the $\mathrm{C}_{2} \mathrm{H}_{2}$ and $\mathrm{CO}_{2}$ adsorption isotherms of SIFSIX-dps-Cu at 273 and $298 \mathrm{~K}$. e comparison of IAST selectivity of representative MOFs for $50 / 50 \mathrm{C}_{2} \mathrm{H}_{2} / \mathrm{CO}_{2}$. $\mathbf{f}$ Comparison about $\mathrm{C}_{2} \mathrm{H}_{2} /$ $\mathrm{CO}_{2}$ selectivity and $\mathrm{C}_{2} \mathrm{H}_{2}$ capacity of representative MOFs at $298 \mathrm{~K}$ and 1 bar.

SNNU-45 $5^{47}$, FJU-90a ${ }^{48}$, UPC-200(Al) ${ }^{49}$, and FJU-6-TATB 50 (Fig. 2f), SIFSIX-dps-Cu and GeFSIX-dps-Cu are still outperforming.

Modeling simulation studies. To investigate the potential $\mathrm{C}_{2} \mathrm{H}_{2}$ adsorption sites in these layered MOFs, dispersion-corrected density functional theory (DFT-D) and grand canonical Monte Carlo (GCMC) simulations are further carried out. Given that it is difficult to get the structures of intermediate states during the dynamic adsorption whereas the structural change during $\mathrm{C}_{2} \mathrm{H}_{2}$ loading is similar to UTSA-300, the activated or open frameworks were thus used for simulations. The distribution density of $\mathrm{C}_{2} \mathrm{H}_{2}$ was investigated firstly at $1 \mathrm{kPa}$, as shown in Fig. 3a, b and Supplementary Figs. 31-33, only $\mathrm{C}_{2} \mathrm{H}_{2}$ can be adsorbed in intralayer cavities (Site I) on all for isoreticular MOFs. As the loading pressure increased to $100 \mathrm{kPa}$, the interlayer cavities (Site II) became accessible by $\mathrm{C}_{2} \mathrm{H}_{2}$ stimuli (Fig. 3b). Such adsorption behavior is in line with that in UTSA-300 confirmed by neutron diffraction data ${ }^{13}$. In contrast, there is no gate-opening sorption for $\mathrm{CO}_{2}$ even at $100 \mathrm{kPa}$ that may be attributed to the opposite molecular quadrupole moment $\left(-13.4 \times 10^{-40} \mathrm{C} \mathrm{m}^{2}\right.$ for $\mathrm{CO}_{2}$ and $+20.5 \times 10^{-40} \mathrm{C} \mathrm{m}^{2}$ for $\left.\mathrm{C}_{2} \mathrm{H}_{2}\right)^{13,51}$. The $\mathrm{C}_{2} \mathrm{H}_{2}$ uptake of SIFSIXdps-Cu, GeFSIX-dps-Cu, and NbOFIVE-dps-Cu was also evaluated by GCMC simulation showing the capacity of 4.40, 3.71, and $1.48 \mathrm{mmol} \mathrm{g}^{-1}$, respectively, which are comparable to their experimental uptakes. Moreover, DFT-D calculations provide insight into the adsorption behaviors and the calculation details are provided in the "Methods" section. The adsorption sites are similar in three dynamic layered MOFs, with $\mathrm{C}_{2} \mathrm{H}_{2}$ molecule bonded by four $\mathrm{F}$ atoms of two distinct fluorinated anion pillars at Site I and Site II via cooperative H...F hydrogen-bond interactions (1.85-2.36 $\AA$, Fig. $3 c$ and Supplementary Fig. 34). The static binding energy of SIFSIX-dps-Cu for $\mathrm{C}_{2} \mathrm{H}_{2}$ is calculated to be 60.3 and $67.5 \mathrm{~kJ} \mathrm{~mol}^{-1}$, respectively, which are also higher than those in GeFSIX-dps-Cu $\left(58.5 \mathrm{~kJ} \mathrm{~mol}^{-1}\right)$ and NbOFFIVEdps-Cu $\left(55.3 \mathrm{~kJ} \mathrm{~mol}^{-1}\right)$. The abundant binding sites with high static binding energies are responsible for the outstanding $\mathrm{C}_{2} \mathrm{H}_{2}$ uptake of SIFSIX-dps-Cu (Fig. 3d). In contrast, $\mathrm{CO}_{2}$ in SIFSIXdps-Cu interacts with pore surface through weak intermolecular interactions like electrostatic interactions $\left(\mathrm{F}^{\delta-} \ldots \mathrm{C}^{\delta+} 2.91-3.63 \AA\right.$, Supplementary Fig. 35). The change in torsion angle between anion pillar and dps ligand caused by $\mathrm{CO}_{2}$ loading is about $18^{\circ}$, which is larger than that for $\mathrm{C}_{2} \mathrm{H}_{2}$ loading $\left(7^{\circ}\right)$, in line with higher gate-opening pressure for $\mathrm{CO}_{2}$ sorption. The experimental isosteric adsorption enthalpy $\left(Q_{\mathrm{st}}\right)$ at zero-coverage for $\mathrm{C}_{2} \mathrm{H}_{2}$ in SIFSIX-dps-Cu is $60.5 \mathrm{~kJ} \mathrm{~mol}^{-1}$ (Supplementary Fig. 36), slightly higher than the $Q_{s t}$ of GeFSIX-dps-Cu $\left(56.3 \mathrm{~kJ} \mathrm{~mol}^{-1}\right)$ and NbOFFIVE-dps-Cu $\left(53.6 \mathrm{~kJ} \mathrm{~mol}^{-1}\right)$.

Transient breakthrough experiments. To confirm the practical $\mathrm{C}_{2} \mathrm{H}_{2} / \mathrm{CO}_{2}$ separation performances of these isoreticular MOFs, experimental breakthrough experiments were conducted with SIFSIX-dps- $\mathrm{Cu}$, GeFSIX-dps-Cu, and NbOFFIVE-dps- $\mathrm{Cu}$ at $298 \mathrm{~K}$. Binary mixture $\left(\mathrm{C}_{2} \mathrm{H}_{2} / \mathrm{CO}_{2}, 50 / 50\right.$, v/v) were injected into a packed column with a flow rate of $2.0 \mathrm{ml} \mathrm{min}^{-1}$ and the clean separations of $\mathrm{C}_{2} \mathrm{H}_{2} / \mathrm{CO}_{2}$ mixtures were realized by all dynamic layered materials (Supplementary Figs. 37 and 38). As expected, SIFSIX-dps- $\mathrm{Cu}$ exhibits the best $\mathrm{C}_{2} \mathrm{H}_{2} / \mathrm{CO}_{2}$ separation performance. In Fig. $4 \mathrm{a}, \mathrm{CO}_{2}$ broke through the bed quickly after feeding the gas mixture into the fixed adsorption column, whereas the $\mathrm{C}_{2} \mathrm{H}_{2}$ was retained in the adsorption bed for $53 \mathrm{ming}^{-1}$. This value is comparable to GeFSIX-dps-Cu $\left(50 \mathrm{~min}^{-1}\right)$ and significantly outperforms NbOFFIVE-dps-Cu (14 min $\mathrm{g}^{-1}$ ) and UTSA-300a $\left(12 \mathrm{~min}^{-1}\right.$ ) at similar conditions. For small roll-up of the breakthrough curves for $\mathrm{CO}_{2}$ in SIFSIXdps- $\mathrm{Cu}$, it can be attributed to the desorption of $\mathrm{CO}_{2}$ induced by $\mathrm{C}_{2} \mathrm{H}_{2}$, which indicates a minor co-adsorption of $\mathrm{CO}_{2}$ during the dynamic capture process and finally displaced by $\mathrm{C}_{2} \mathrm{H}_{2}$. That phenomenon is consistent with the minor $\mathrm{CO}_{2}$ uptake from single-component sorption isotherms. The $\mathrm{C}_{2} \mathrm{H}_{2}$ and $\mathrm{CO}_{2}$ adsorption kinetics in SIFSIX-dps-Cu showed no significant $\mathrm{CO}_{2}$ uptake under a sufficiently long period of time but rapid $\mathrm{C}_{2} \mathrm{H}_{2}$ 
a

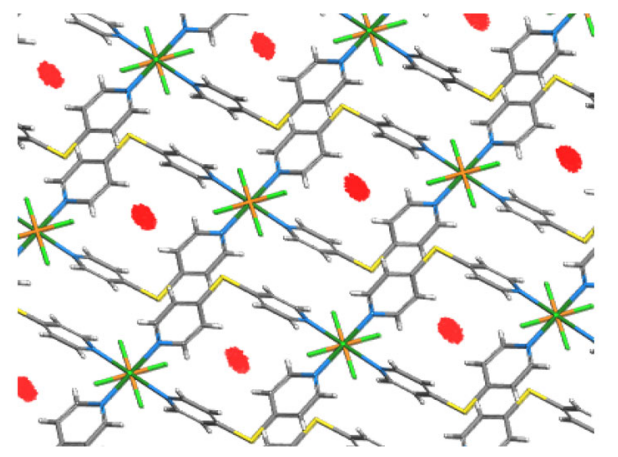

C

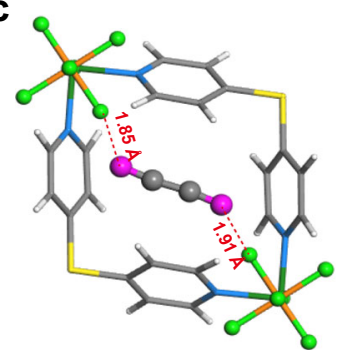

b

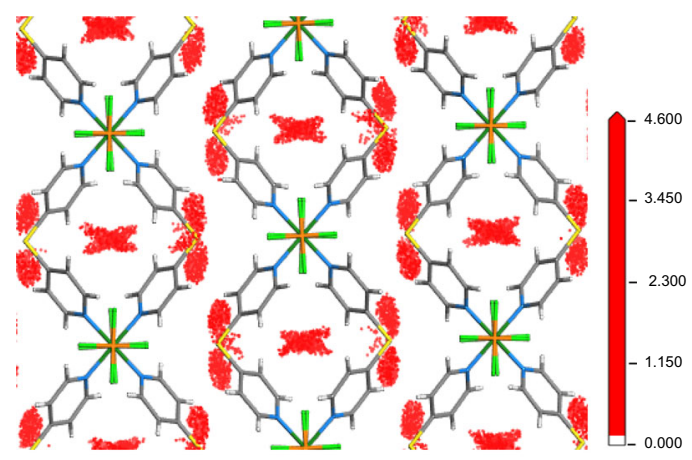

d

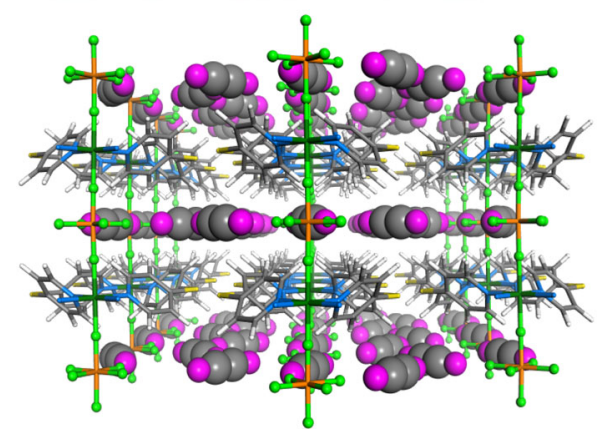

Fig. 3 Simulated density distribution of $\mathbf{C}_{\mathbf{2}} \mathbf{H}_{\mathbf{2}}$ in SIFSIX-dps-Cu. $\mathrm{C}_{2} \mathrm{H}_{2}$ distributions in SIFSIX-dps-Cu by GCMC simulation $\mathbf{a}$ at $1 \mathrm{kPa}$ and $\mathbf{b}$ at $100 \mathrm{kPa}$ and $298 \mathrm{~K}$, viewed along the $\left(\mathrm{CuSiF}_{6}\right)_{\infty}$ chains. c DFT-D calculated $\mathrm{C}_{2} \mathrm{H}_{2}$ binding mode in SIFSIX-dps-Cu. d Packing mode of $\mathrm{C}_{2} \mathrm{H}_{2}$-loaded SIFSIX-dps-Cu structure.

a

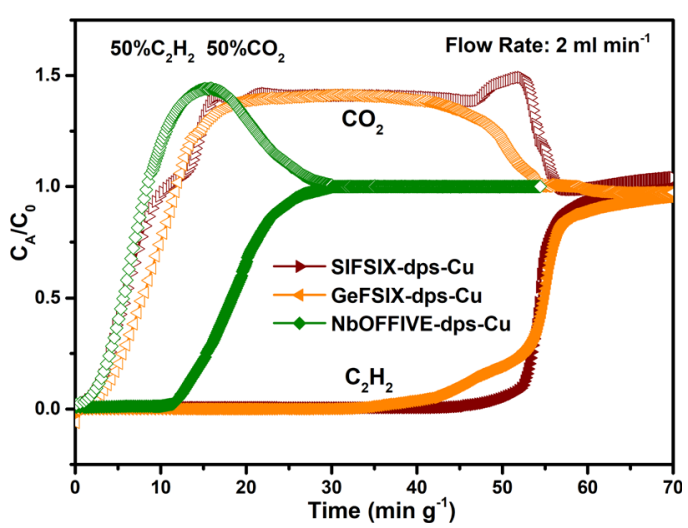

C

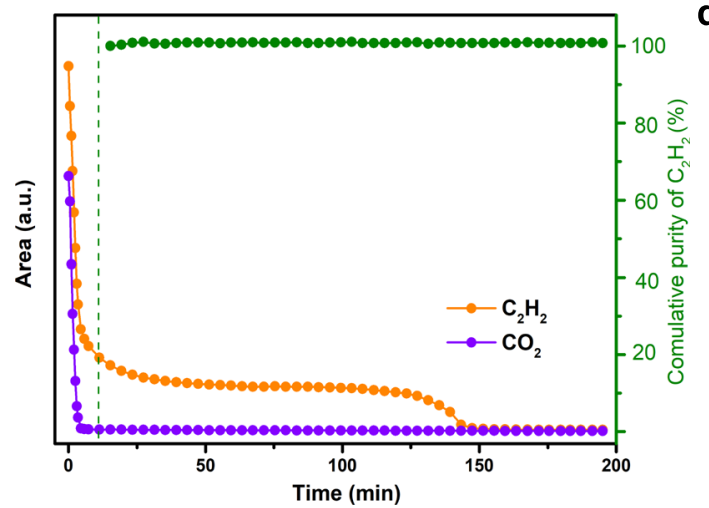

b

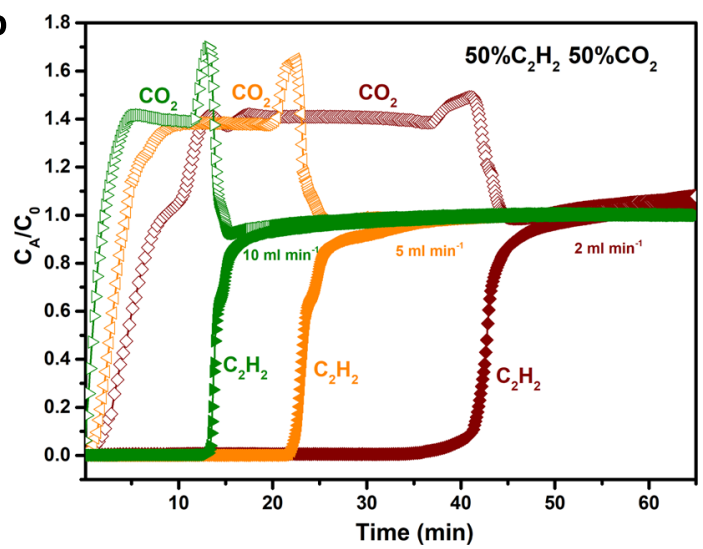

d

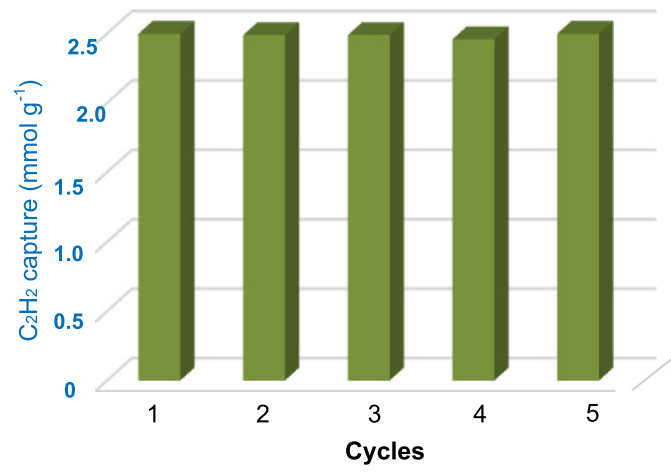

Fig. $4 \mathbf{C}_{\mathbf{2}} \mathbf{H}_{\mathbf{2}} / \mathbf{C O}_{\mathbf{2}}$ separation. Breakthrough curves of $\mathrm{C}_{2} \mathrm{H}_{2} / \mathrm{CO}_{2}(50 / 50)$ in a representative MOFs with a $2 \mathrm{ml} \mathrm{min}^{-1}$ flow rate at $298 \mathrm{~K}$. b The breakthrough curves with different flow rates at $298 \mathrm{~K}$. c The signals of desorbed gases from SIFSIX-dps-Cu. d Cycling stability of SIFSIX-dps-Cu for $\mathrm{C}_{2} \mathrm{H}_{2} /$ $\mathrm{CO}_{2}(50 / 50)$ separation. 
saturation with a capacity of $3.72 \mathrm{mmol} \mathrm{g}^{-1}$ at 0.5 bar and $298 \mathrm{~K}$, indicating that $\mathrm{CO}_{2}$ cannot diffuse into the framework of SIFSIXdps-Cu (Supplementary Fig. 39). At 5 and $10 \mathrm{ml} \mathrm{min}^{-1}$, the rollup phenomenon becomes significant that might induce by faster gas displacement at a higher flow rate (Fig. 4b). Moreover, the adsorbent could be completely regenerated with a He flows rate of $10 \mathrm{ml} \mathrm{min}^{-1}$ at $298 \mathrm{~K}$. In the desorption process, $\mathrm{CO}_{2}$ will be eluted immediately, and then high-purity $\mathrm{C}_{2} \mathrm{H}_{2}$ product $(\geq 99.9 \%)$ can be collected in the interior of the packed column for $137 \mathrm{~min}$ (Fig. 4c). This result also demonstrated the negligible coadsorption of $\mathrm{CO}_{2}$. For the minor inconsistency between the $\mathrm{CO}_{2}$ breakthrough curve and equilibrium $\mathrm{CO}_{2}$ isotherm of NbOFFIVE-dps-Cu, it can be attributed to the preferential capture of $\mathrm{C}_{2} \mathrm{H}_{2}$ from the dynamic gas flow by this MOF that inhibits $\mathrm{CO}_{2}$ adsorption, as indicated by distinctly different adsorption heats $\left(\mathrm{C}_{2} \mathrm{H}_{2}: 53.6 \mathrm{~kJ} \mathrm{~mol}^{-1}, \mathrm{CO}_{2}: 28.8 \mathrm{~kJ} \mathrm{~mol}^{-1}\right)$ and dual-components adsorption result (Supplementary Fig. 17). The corresponding desorption curves of NbOFFIVE-dps-Cu in the regeneration process after $\mathrm{C}_{2} \mathrm{H}_{2} / \mathrm{CO}_{2}$ breakthrough have also confirmed negligible $\mathrm{CO}_{2}$ co-adsorption (Supplementary Fig. 40).

Furthermore, the $\mathrm{C}_{2} \mathrm{H}_{2}$ productivity of SIFSIX-dps-Cu calculated from the breakthrough curve is $2.48 \mathrm{mmol} \mathrm{g}^{-1}$, which outperforms those of CPL-1- $\mathrm{NH}_{2}(1.38 \mathrm{mmol} \mathrm{g}-1)^{41}$, and is comparable to SIFSIX-3-Ni $(2.5 \mathrm{mmolg}-1)^{44}$. And the $\mathrm{C}_{2} \mathrm{H}_{2}$ productivity of GeFSIX-dps-Cu and NbOFFIVE-dps-Cu was calculated to be 2.36 and $0.83 \mathrm{mmol} \mathrm{g}^{-1}$, respectively, which are significantly superior to that of UTSA-300a $\left(0.77 \mathrm{mmol} \mathrm{g}^{-1}\right)^{13}$. In particular, these results validate the flexible-robust pore space of these dynamic MOFs for simultaneous high $\mathrm{C}_{2} \mathrm{H}_{2}$ capacity and $\mathrm{C}_{2} \mathrm{H}_{2} / \mathrm{CO}_{2}$ selectivity. It should be noted that the $\mathrm{C}_{2} \mathrm{H}_{2}$ productivity of the three MOFs calculated from breakthrough curves is lower than those of corresponding maximum adsorption capacity $\left(4.57,4.04\right.$, and $1.65 \mathrm{mmol} \mathrm{g}^{-1}$ for SIFSIX-dps-Cu, GeFSIX-dps-Cu, and NbOFFIVE-dps-Cu, respectively), which might be attributed to the inter-framework diffusional resistances. For practical industrial applications, the adsorbents are expected to show good recyclability. Thus, five successive $\mathrm{C}_{2} \mathrm{H}_{2} / \mathrm{CO}_{2}$ dynamic breakthrough experiments were carried out on SIFSIXdps-Cu, GeFSIX-dps-Cu, and NbOFFIVE-dps-Cu at three flow rates, and negligible deteriorations in breakthrough time and working capacity during five cycles indicates their outstanding recyclability (Fig. 4d and Supplementary Fig. 38). Furthermore, PXRD and sorption studies upon various conditions show that SIFSIX-dps-Cu can maintain its crystallinity in water, several organic solvents or under moisture for at least 7 days (Supplementary Fig. 41).

\section{Discussion}

The adsorption behaviors in a series of isoreticular MOFs have been successfully controlled as a result of pore size adjustment through altering the anionic linkers, and thus realizing highly efficient $\mathrm{C}_{2} \mathrm{H}_{2} / \mathrm{CO}_{2}$ separations. After tuning with dual functionality namely appropriate pore size and specific functional sites, novel adsorbent variants can exhibit both excellent $\mathrm{C}_{2} \mathrm{H}_{2}$ uptake and $\mathrm{C}_{2} \mathrm{H}_{2} / \mathrm{CO}_{2}$ selectivity at ambient conditions. The precise pore engineering would apply to many other MOFs regarding basic principles in MOF chemistry. This work illustrates a good example to realize high-performance materials for molecular recognition and will inspire future designs on novel porous materials.

\section{Methods}

All reagents were purchased from commercial companies and used without further purification.
Synthesis of SIFSIX-dps-Cu. The sample was prepared according to ref. ${ }^{39}$, and reproduced here for completeness. A methanol solution $(5.0 \mathrm{ml})$ of dps $(0.054 \mathrm{~g}$, $0.286 \mathrm{mmol})$ was slowly added to an aqueous solution $(5.0 \mathrm{ml})$ of $\mathrm{Cu}\left(\mathrm{BF}_{4}\right)_{2} \cdot x \mathrm{H}_{2} \mathrm{O}$ $(0.066 \mathrm{~g}, 0.26 \mathrm{mmol})$ and $\left(\mathrm{NH}_{4}\right)_{2} \mathrm{SiF}_{6}(0.046 \mathrm{~g}, 0.26 \mathrm{mmol})$ at room temperature, the mixture was kept undisturbed at room temperature for $48 \mathrm{~h}$. Then the purple powder was washed with methanol and dried under a high vacuum at room temperature for $24 \mathrm{~h}$.

Synthesis of GeFSIX-dps-Cu. A methanol solution $(5.0 \mathrm{ml})$ of dps $(0.054 \mathrm{~g}$, $0.286 \mathrm{mmol})$ was slowly added to an aqueous solution $(5.0 \mathrm{ml})$ of $\mathrm{Cu}\left(\mathrm{BF}_{4}\right)_{2} \cdot x \mathrm{H}_{2} \mathrm{O}$ $(0.066 \mathrm{~g}, 0.26 \mathrm{mmol})$ and $\left(\mathrm{NH}_{4}\right)_{2} \mathrm{GeF}_{6}(0.058 \mathrm{~g}, 0.26 \mathrm{mmol})$ at room temperature, the mixture was kept undisturbed at room temperature for $48 \mathrm{~h}$. Then the purple powder was washed with methanol and dried under a high vacuum at room temperature for $24 \mathrm{~h}$.

The single crystals of GeFSIX-dps-Cu were synthesized by the slow diffusion of a methanol solution $(1.0 \mathrm{ml})$ of dps $(0.011 \mathrm{~g}, 0.057 \mathrm{mmol})$ into an aqueous solution $(1.0 \mathrm{ml})$ of $\mathrm{Cu}\left(\mathrm{BF}_{4}\right)_{2} \cdot x \mathrm{H}_{2} \mathrm{O}(0.013 \mathrm{~g}, 0.052 \mathrm{mmol})$ and $\left(\mathrm{NH}_{4}\right)_{2} \mathrm{GeF}_{6}(0.012 \mathrm{~g}$, $0.052 \mathrm{mmol}$ ) at room temperature in a watch glass without stirring. Specifically, $0.5 \mathrm{ml}$ of $1: 1 \mathrm{methanol} / \mathrm{H}_{2} \mathrm{O}$ was layered between the top and bottom solutions to slow the rate of reaction. Light purple and rectangular prismatic crystals formed after 4 days.

Synthesis of NbOFFIVE-dps-Cu. A methanol solution $(5.0 \mathrm{ml})$ of dps $(0.054 \mathrm{~g}$, $0.286 \mathrm{mmol})$ was slowly added to an aqueous solution $(5.0 \mathrm{ml})$ of $\mathrm{Cu}\left(\mathrm{BF}_{4}\right)_{2} \cdot x \mathrm{H}_{2} \mathrm{O}$ $(0.066 \mathrm{~g}, 0.26 \mathrm{mmol})$ and $\left(\mathrm{NH}_{4}\right)_{2} \mathrm{NbF}_{6}(0.059 \mathrm{~g}, 0.26 \mathrm{mmol})$ at room temperature, the mixture was kept undisturbed at room temperature for $48 \mathrm{~h}$. Then the purple powder was washed with methanol and dried under a high vacuum at room temperature for $24 \mathrm{~h}$.

The single crystals of NbOFFIVE-dps-Cu were synthesized by the slow diffusion of a methanol solution $(1.0 \mathrm{ml})$ of dps $(0.011 \mathrm{~g}, 0.057 \mathrm{mmol})$ into an aqueous solution $(1.0 \mathrm{ml})$ of $\mathrm{Cu}\left(\mathrm{BF}_{4}\right)_{2} \cdot x \mathrm{H}_{2} \mathrm{O}(0.013 \mathrm{~g}, 0.052 \mathrm{mmol})$ and $\left(\mathrm{NH}_{4}\right)_{2} \mathrm{NbF}_{6}(0.012 \mathrm{~g}, 0.052 \mathrm{mmol})$ at room temperature in a watch glass without stirring. Specifically, $0.5 \mathrm{ml}$ of $1: 1 \mathrm{methanol} / \mathrm{H}_{2} \mathrm{O}$ was layered between the top and bottom solutions to slow the rate of reaction. Light purple and rectangular prismatic crystals formed after 4 days.

X-ray diffraction structure analysis. PXRD patterns were measured by a PANalytical Empyrean Series 2 diffractometer with $\mathrm{Cu}$ Ka radiation with a step size of $0.0167^{\circ}$, a scan time of $15 \mathrm{~s}$ per step, and $2 \theta$ ranging from 5 to $90^{\circ}$ at room temperature.

Single-crystal X-ray diffraction. Single crystal X-ray diffraction data for GeFSIX dps-Cu and NbOFFIVE-dps-Cu were collected at 193(2) K on a Bruker-AXS D8 VENTURE diffractometer equipped with a PHOTON-100/CMOS detector (GaKa, $\lambda=1.3414 \AA$ ). Indexing was performed using APEX2. SaintPlus 6.01 was used to complete data integration and reduction. The multi-scan method implemented in SADABS was used to conduct absorption correction. XPREP implemented in APEX2.1 was used to determine the space group. The structures were solved by direct methods and refined by nonlinear least-squares on $F^{2}$ (method) with SHELXL-97 contained in APEX2, OLEX2 v1.1.5, and WinGX v1.70.01 program packages. All non-hydrogen atoms were refined anisotropically. The Squeeze routine implemented in Platon was used to treat the contribution of disordered solvent molecules as diffuse.

The thermogravimetric analysis (TGA). The thermogravimetric analysis (TGA) data were collected in a NETZSCH Thermogravimetric Analyzer (STA2500) from 25 to $700{ }^{\circ} \mathrm{C}$ with a heating rate of $10^{\circ} \mathrm{C} / \mathrm{min}$.

Gas sorption measurements. A Micromeritics ASAP 2460 adsorption apparatus was used to measure gas adsorption isotherms. In order to remove all the guest solvents in the framework, the fresh powder samples were evacuated under a high vacuum at room temperature $(298 \mathrm{~K})$ for $72 \mathrm{~h}$. Liquid nitrogen and dry ice-acetone bath were used for adsorption isotherms at 77 or $196 \mathrm{~K}$. The helium gas was used to determine the free space of the system. The degas procedure was repeated on the same sample between measurements for $24 \mathrm{~h}$.

Calculation of isosteric heat of adsorption $\left(\mathbf{Q}_{\mathbf{s t}}\right)$. The experimental adsorption enthalpy $\left(Q_{\mathrm{st}}\right)$ was applied to evaluate the binding strength between adsorbent and adsorbate, defined as

$$
Q_{\mathrm{st}}=\mathrm{RT}^{2}\left(\frac{\partial \ln p}{\partial T}\right)
$$

The isosteric heat of adsorption, $Q_{\mathrm{st}}$ is determined using the pure component isotherm fits using the Clausius-Clapeyron equation, where $Q_{\mathrm{st}}\left(\mathrm{kJ} \mathrm{mol}^{-1}\right)$ is the isosteric heat of adsorption, $T(\mathrm{~K})$ is the temperature, $p(\mathrm{kPa})$ is the pressure, and $R$ is the gas constant. 
DFT calculations. The first-principles DFT calculations were proceeded using the Quantum-Espresso package ${ }^{52}$. van der Waals interactions were illustrated by the calculation with a semiempirical addition of dispersive forces to the conventional $\mathrm{DFT}^{53}$. Vanderbilt-type ultrasoft pseudopotentials and generalized gradient approximation (GGA) with a Perdew-Burke-Ernzerhof were used for exchangecorrelation. We found that cutoff energy of $544 \mathrm{eV}$ and a $2 \times 2 \times 2 \mathrm{k}$-point mesh (generated using the Monkhosrt-Pack scheme) were enough for the total energy to converge within $0.01 \mathrm{meV} /$ atom. Fully open structures were used for the calculations of binding energy. First, the structure was optimized. Afterward, the various guest gas molecules were placed to various locations of the pore structure, followed by a full structural relaxation. To gain the gas binding energy, an isolated gas molecule that was placed in a supercell (with the same cell dimensions as the MOF crystal) was also relaxed. The static binding energy (at $T=0 \mathrm{~K}$ ) was then calculated using $E_{\mathrm{B}}=E(\mathrm{MOF})+E($ gas $)-E(\mathrm{MOF}+$ gas $)$.

GCMC simulations. The GCMC simulations which were carried out to investigate the adsorbed capacity of wavy layered MOFs for $\mathrm{C}_{2} \mathrm{H}_{2} / \mathrm{CO}_{2}$ at $298 \mathrm{~K}$ from 0.001 to $100 \mathrm{kPa}$ were performed by sorption code in MS software. Activated structures were used for the simulation of adsorption before gate-opening, whereas fully open structures were used for the simulation of adsorption after gate-opening. We used a simulation box with a $1 \times 1 \times 1$ crystallographic unit cell. During the simulations, in order to guarantee the equilibration and to sample the desired properties, $4 \times 10^{6}$ steps were performed. In all simulations, a rigid framework assumption was employed. We describe the interactions using the Dreiding forcefield parameter12, Lenard-Jones 12-6 potential was used to depict the van der Waals interaction with a cutoff of $15.5 \AA^{12}$.

The GCMC simulations were performed in the NVT ensemble to calculate the isosteric heats of adsorption $Q_{\mathrm{st}}$. The internal energy $\Delta U$ was computed during the simulation, which is directly related to $Q_{\text {st. }}$. The isosteric heat of adsorption $Q_{\text {st }}$ was calculated from

$$
Q_{\mathrm{st}}=\mathrm{RT}-\frac{\left\langle U_{f f} N\right\rangle-\left\langle U_{f f}\right\rangle\langle N\rangle}{\left\langle N^{2}\right\rangle-\langle N\rangle\langle N\rangle}-\frac{\left\langle U_{s f} N\right\rangle-\left\langle U_{s f}\right\rangle\langle N\rangle}{\left\langle N^{2}\right\rangle-\langle N\rangle\langle N\rangle}
$$

where $R$ is the gas constant, $N$ is the number of molecules adsorbed, and \langle\rangle indicates the ensemble average. The $U_{\mathrm{ff}}$ in the first and second terms are the contributions from the molecular thermal energy and adsorbate-adsorbate interaction energy, respectively. The $U_{\text {sf }}$ in the third term is the contribution from the adsorbent-adsorbate interaction energy.

IAST calculations. In order to calculate the selective sorption performance for SIFSIX-dps-Cu, GeFSIX-dps-Cu, and NbOFFIVE-dps-Cu toward the separation of binary mixed gases, the fitting of single-component $\mathrm{C}_{2} \mathrm{H}_{2}$ and $\mathrm{CO}_{2}$ adsorption isotherms were carried out based on the DSLF model. The fitting parameters of the DSLF equation are displayed in Supplementary Table 7. Adsorption isotherms and gas selectivities of mixed $\mathrm{C}_{2} \mathrm{H}_{2} / \mathrm{CO}_{2}(50 / 50$, v/v) at $298 \mathrm{~K}$ were predicted using the IAST. The results are shown in Supplementary Figs. 22-27.

DSLF model is listed below

$$
N=N_{1}^{\max } \times \frac{b_{1} p^{1 / n 1}}{1+b_{1} p^{1 / n 1}}+N_{2}^{\max } \times \frac{b_{2} p^{1 / \mathrm{n} 2}}{1+b_{2} p^{1 / \mathrm{n} 2}}
$$

Where $p$ (unit: $\mathrm{kPa}$ ) is the pressure of the bulk gas at equilibrium with the adsorbed phase, $N$ (unit: mol $/ \mathrm{kg}$ ) is the adsorbed amount per mass of adsorbent, $N_{1}{ }^{\max }$ and $\mathrm{N}_{2}{ }^{\max }$ (unit: $\mathrm{mmol} / \mathrm{g}$ ) are the saturation capacities of two different sites, $b_{1}$ and $b_{2}$ (unit: $1 / \mathrm{kPa}$ ) are the affinity coefficients of these sites, and $n_{1}$ and $n_{2}$ represent the deviations from an ideal homogeneous surface.

The adsorption selectivity for the mixtures $\mathrm{C}_{2} \mathrm{H}_{2} / \mathrm{CO}_{2}$ is defined by

$$
S_{\mathrm{ads}}=\frac{q_{1} / q_{2}}{p_{1} / p_{2}}
$$

were calculated according to the IAST model proposed by Myers ${ }^{54,55}$, in the above equation, $q_{1}$ and $q_{2}$ are the absolute component loadings of the adsorbed phase in the mixture. These component loadings are also termed uptake capacities.

Transient breakthrough experiments. The breakthrough experiments were carried out in a homemade apparatus. The feeding streams are gas-mixtures of 50/50 (v/v) $\mathrm{C}_{2} \mathrm{H}_{2} / \mathrm{CO}_{2}$ with a flow rate of $2 \mathrm{ml} \mathrm{min}^{-1}$ ( $298 \mathrm{~K}$ and 1.01 bar). The mass packed in the sample holder was: SIFSIX-dps-Cu (0.7881 g), GeFSIX-dps-Cu $(0.7624 \mathrm{~g})$, and NbOFFIVE-dps-Cu $(0.7313 \mathrm{~g})$. Activated samples were packed into a $\Phi 6.3 \times 140 \mathrm{~mm}$ stainless steel column. A carrier gas $(\mathrm{He} \geq 99.999 \%)$ was used to purge the adsorption bed for about $12 \mathrm{~h}$ at room temperature. A mass flow meter was used to regulate the gas flows, and the outlet gas from the column was monitored using mass spectrometry (Hidden, UK).) After each separation test, the sample was regenerated with a $\mathrm{He}$ flow of $15 \mathrm{ml} \mathrm{min}^{-1}$ at $298 \mathrm{~K}$. Ultrahigh purity grade helium (99.999\%), acetylene (>99\%), carbon dioxide (99\%), and nitrogen (99.999\%) were purchased from Nanchang Guoteng Gas Co., Ltd. (China).

\section{Data availability}

All data supporting the finding of this study are available within this article and its Supplementary Information. Crystallographic data for the structures in this article have been deposited at the Cambridge Crystallographic Data Centre under deposition Nos. CCDC 2060207 (GeFSIX-dps-Cu) and 2060208 (NbOFFIVE-dps-Cu). Copies of the data can be obtained free of charge from www.ccdc.cam.ac.uk/data_request/cif. Source data that support the findings of this study are available from the corresponding author upon request. Additional graphics, model fitting, and calculations are available within its Supplementary Information.

Received: 20 May 2021; Accepted: 21 December 2021; Published online: 11 January 2022

\section{References}

1. Moreau, F. et al. Unravelling exceptional acetylene and carbon dioxide adsorption within a tetra-amide functionalized metal-organic framework. Nat. Commun 8, 14085 (2017).

2. Zhang, Y. et al. Rational design of microporous MOFs with anionic boron cluster functionality and cooperative dihydrogen binding sites for highly selective capture of acetylene. Angew. Chem. Int. Ed. 59, 17664-17669 (2020).

3. Pei, J. et al. A chemically stable Hofmann-type metal-organic framework with sandwich-like binding sites for benchmark acetylene capture. Adv. Mater. 32, 1908275 (2020).

4. Matsuda, R. et al. Highly controlled acetylene accommodation in a metal-organic microporous material. Nature 436, 238-241 (2005).

5. Zeng, $\mathrm{H}$. et al. Induced fit of $\mathrm{C}_{2} \mathrm{H}_{2}$ in a flexible MOF through cooperative action of open metal sites. Angew. Chem. Int. Ed. 58, 8515-8519 (2019).

6. Xie, Y. et al. Electrostatically driven selective adsorption of carbon dioxide over acetylene in an ultramicroporous material. Angew. Chem. Int. Ed. 60, 9604-9609 (2021).

7. Gao, J. et al. Mixed metal-organic framework with multiple binding sites for efficient $\mathrm{C}_{2} \mathrm{H}_{2} / \mathrm{CO}_{2}$ separation. Angew. Chem. Int. Ed. 59, 4396-4400 (2020).

8. Foo, M. L. et al. An adsorbate discriminatory gate effect in a flexible porous coordination polymer for selective adsorption of $\mathrm{CO}_{2}$ over $\mathrm{C}_{2} \mathrm{H}_{2}$. J. Am. Chem. Soc. 138, 3022-3030 (2016)

9. Niu, Z. et al. A MOF-based ultra-strong acetylene nano-trap for highly efficient $\mathrm{C}_{2} \mathrm{H}_{2} / \mathrm{CO}_{2}$ separation. Angew. Chem. Int. Ed. 60, 5283-5288 (2021).

10. Adil, K., Belmabkhout, Y., Cadiau, A., Eddaoudi, M. \& Bhatt, P. M. A metalorganic framework-based splitter for separating propylene from propane. Science 353, 137-140 (2016)

11. Zhu, B. et al. Pore engineering for one-step ethylene purification from a three-component hydrocarbon mixture. J. Am. Chem. Soc. 143, 1485-1492 (2021).

12. $\mathrm{Xu}, \mathrm{Z}$. et al. A robust Th-azole framework for highly efficient purification of $\mathrm{C}_{2} \mathrm{H}_{4}$ from a $\mathrm{C}_{2} \mathrm{H}_{4} / \mathrm{C}_{2} \mathrm{H}_{2} / \mathrm{C}_{2} \mathrm{H}_{6}$ mixture. Nat. Commun. 11, 3163 (2020).

13. Lin, R.-B. et al. Optimized separation of acetylene from carbon dioxide and ethylene in a microporous material. J. Am. Chem. Soc. 139, 8022-8028 (2017).

14. Liu, S. et al. Efficient separation of acetylene and carbon dioxide in a decorated Zeolite. Angew. Chem. Int. Ed. 60, 6526-6532 (2021).

15. Xue, Y. et al. Precise pore space partitions combined with high-density hydrogen-bonding acceptors within metal-organic frameworks for highly efficient acetylene storage and separation. Angew. Chem. Int. Ed. 60, 10122-10128 (2021).

16. Trenholme, W. J. F. et al. Selective gas uptake and rotational dynamics in a $(3,24)$-connected metal-organic framework material. J. Am. Chem. Soc. 143, 3348-3358 (2021).

17. Liu, J. et al. Ammonia capture within zirconium metal-organic frameworks: reversible and irreversible uptake. ACS Appl. Mater. Interfaces $\mathbf{1 3}$ 20081-20093 (2021)

18. Zhang, Z. et al. Efficient trapping of trace acetylene from ethylene in an ultramicroporous metal-organic framework: synergistic effect of high-density open metal and electronegative sites. Angew. Chem. Int. Ed. 59, 18927-18932 (2020).

19. Antypov, D. et al. Differential guest location by host dynamics enhances propylene/propane separation in a metal-organic framework. Nat. Commun. 11, 6099 (2020)

20. Chen, Y. et al. Structural diversity of zirconium metal-organic frameworks and effect on adsorption of toxic chemicals. J. Am. Chem. Soc. 142, 21428-21438 (2020).

21. Wang, Y. et al. One-step ethylene purification from an acetylene/ethylene/ ethane ternary mixture by cyclopentadiene cobalt-functionalized metalorganic frameworks. Angew. Chem. Int. Ed. 60, 11350-11358 (2021)

22. Lysova, A. A. et al. A series of mesoporous metal-organic frameworks with tunable windows sizes and exceptionally high ethane over ethylene adsorption selectivity. Angew. Chem. Int. Ed. 59, 20561-20567 (2020). 
23. Wang, Y. et al. A strategy for constructing pore-space-partitioned MOFs with high uptake capacity for $\mathrm{C}_{2}$ hydrocarbons and $\mathrm{CO}_{2}$. Angew. Chem. Int. Ed. 59, 19027-19030 (2020).

24. Duan, J. et al. Density gradation of open metal sites in the mesospace of porous coordination polymers. J. Am. Chem. Soc. 139, 11576-11583 (2017)

25. Wang, H., Liu, Y. \& Li, J. Designer metal-organic frameworks for sizeexclusion-based hydrocarbon separations: progress and challenges. Adv. Mater. 32, 2002603 (2020).

26. $\mathrm{Li}, \mathrm{X}$. et al. Refinement of pore size at sub-angstrom precision in robust metal-organic frameworks for separation of xylenes. Nat. Commun. 11, 4280 (2020).

27. Li, H. et al. An unprecedented pillar-cage fluorinated hybrid porous framework with highly efficient acetylene storage and separation. Angew. Chem. Int. Ed. 60, 7547-7552 (2021)

28. Cui, X. et al. Pore chemistry and size control in hybrid porous materials for acetylene capture from ethylene. Science 353, 141-144 (2016)

29. Nugent, P. et al. Enhancement of $\mathrm{CO}_{2}$ selectivity in a pillared pcu MOM platform through pillar substitution. Chem. Commun. 49, 1606-1608 (2013).

30. Mukherjee, S. et al. Amino-functionalised hybrid ultramicroporous materials that enable single-step ethylene purification from a ternary mixture. Angew. Chem. Int. Ed. 60, 10902-10909 (2021).

31. Yang, L. et al. A single-molecule propyne trap: highly efficient removal of propyne from propylene with anion-pillared ultramicroporous materials. Adv. Mater. 30, 1705374 (2018).

32. Zhang, $Z$. et al. Sorting of $\mathrm{C}_{4}$ olefins with interpenetrated hybrid ultramicroporous materials by combining molecular recognition and sizesieving. Angew. Chem. Int. Ed. 56, 16282-16287 (2017).

33. Qazvini, O. T., Babarao, R. \& Telfer, S. G. Selective capture of carbon dioxide from hydrocarbons using a metal-organic framework. Nat. Commun. 12, 197 (2021).

34. Dong, Q. et al. Tuning gate-opening of a flexible metal-organic framework for ternary gas sieving separation. Angew. Chem. Int. Ed. 59, 22756-22762 (2020).

35. Wang, Q. et al. Separation of Xe from $\mathrm{Kr}$ with record selectivity and productivity in anion-pillared ultramicroporous materials by inverse sizesieving. Angew. Chem. Int. Ed. 59, 3423-3428 (2020)

36. Wang, H. et al. Crystallizing atomic xenon in a flexible MOF to probe and understand its temperature-dependent breathing behavior and unusual gas adsorption phenomenon. J. Am. Chem. Soc. 142, 20088-20097 (2020).

37. Zhang, J.-P. \& Chen, X.-M. Optimized acetylene/carbon dioxide sorption in a dynamic porous crystal. J. Am. Chem. Soc. 131, 5516-5521 (2009).

38. He, C.-T. et al. Hyperfine adjustment of flexible pore-surface pockets enables smart recognition of gas size and quadrupole moment. Chem. Sci. 8, 7560-7565 (2017).

39. Wang, J. et al. Optimizing pore space for flexible-robust metal-organic framework to boost trace acetylene removal. J. Am. Chem. Soc. 142, 9744-9751 (2020).

40. Ke, T. et al. Molecular sieving of C2-C3 alkene from alkyne with tuned threshold pressure in robust layered metal-organic frameworks. Angew. Chem. Int. Ed. 59, 12725-12730 (2020).

41. Yang, L. Z. et al. Adsorption site selective occupation strategy within a metal-organic framework for highly efficient sieving acetylene from carbon dioxide. Angew. Chem. Int. Ed. 60, 4570-4574 (2021).

42. Shen, J. et al. Simultaneous interlayer and intralayer space control in twodimensional metal-organic frameworks for acetylene/ethylene separation. Nat. Commun. 11, 6259 (2020).

43. Hamon, L. et al. Co-adsorption and separation of $\mathrm{CO}_{2}-\mathrm{CH}_{4}$ mixtures in the highly flexible MIL-53(Cr) MOF. J. Am. Chem. Soc. 131, 17490-17499 (2009).

44. Chen, $\mathrm{K}$. et al. Benchmark $\mathrm{C}_{2} \mathrm{H}_{2} / \mathrm{CO}_{2}$ and $\mathrm{CO}_{2} / \mathrm{C}_{2} \mathrm{H}_{2}$ separation by two closely related hybrid ultramicroporous materials. Chemistry 1, 753-765 (2016).

45. Luo, F. et al. UTSA-74: A MOF-74 isomer with two accessible binding sites per metal center for highly selective gas separation. J. Am. Chem. Soc. 138, 5678-5684 (2016).

46. Ma, J. X. et al. Microporous lanthanide metal-organic framework constructed from lanthanide metalloligand for selective separation of $\mathrm{C}_{2} \mathrm{H}_{2} / \mathrm{CO}_{2}$ and $\mathrm{C}_{2} \mathrm{H}_{2} / \mathrm{CH}_{4}$ at room temperature. Inorg. Chem. 56, 7145-7150 (2017).

47. Li, Y. P. et al. Ultramicroporous building units as a path to bi-microporous metal-organic frameworks with high acetylene storage and separation performance. Angew. Chem. Int. Ed. 58, 13590-13595 (2019).

48. Ye, Y. et al. Pore space partition within a metal-organic framework for highly efficient $\mathrm{C}_{2} \mathrm{H}_{2} / \mathrm{CO}_{2}$ separation. J. Am. Chem. Soc. 141, 4130-4136 (2019).
49. Fan, W. et al. Optimizing multivariate metal-organic frameworks for efficient $\mathrm{C}_{2} \mathrm{H}_{2} / \mathrm{CO}_{2}$ separation. J. Am. Chem. Soc. 142, 8728-8737 (2020)

50. Liu, L. et al. Integrating pillared-layer strategy and pore-space partition method to construct multicomponent MOFs for $\mathrm{C}_{2} \mathrm{H}_{2} / \mathrm{CO}_{2}$ separation. J. Am. Chem. Soc. 142, 9258-9266 (2020).

51. Junquera-Hernández, J. M., Sánchez-Marín, J. \& Maynau, D. Molecular electric quadrupole moments calculated with matrix dressed SDCI. Chem. Phys. Lett. 359, 343-348 (2002).

52. Giannozzi, P. et al. QUANTUM ESPRESSO: a modular and open-source software project for quantum simulations of materials. J. Phys. Condens. Matter 21, 395502 (2009).

53. Hashmi, S. \& Al-Salam, S. Acute myocardial infarction and myocardial ischemia-reperfusion injury: a comparison. Int. J. Clin. Exp. Pathol. 8, 8786-8796 (2015).

54. Myers, A. L. Equation of state for adsorption of gases and their mixtures in porous materials. Adsorption 9, 9-16 (2003).

55. Myers, A. L. \& Prausnitz, J. M. Thermodynamics of mixed-gas adsorption. AIChE J. 11, 121-127 (1965).

\section{Acknowledgements}

The research work was supported by the National Natural Science Foundation of China Nos. 21908090 and 22168023 (J.W.), and 22008099 (Z.Y.); Hundred Talents Program of Sun Yat-Sen University (R.-B.L.); the Natural Science Foundation of Jiangxi Province No. 20192ACB21015 (J.W.); and Welch Foundation AX-1730 (B.C.).

\section{Author contributions}

J.W., B.C., S.D., and R.-B.L. conceived the project and designed the research, and cowrote the paper. J.W. and Y.Z. designed the MOF materials. J.W. and Y.Z. carried out the materials synthesis and adsorption experiments. S.Y. and X.L. carried out conducted column breakthrough measurements. P.X. and S.C. performed the IAST calculation and simulation. Z.Z. and Q.D. collected and analyzed X-ray diffraction data. All authors contributed to the discussion of results and commented on the paper.

\section{Competing interests}

The authors declare no competing interests.

\section{Additional information}

Supplementary information The online version contains supplementary material available at https://doi.org/10.1038/s41467-021-27929-7.

Correspondence and requests for materials should be addressed to Rui-Biao Lin, Shuguang Deng or Banglin Chen.

Peer review information Nature Communications thanks De-Li Chen and the other anonymous, reviewer(s) for their contribution to the peer review of this work. Peer reviewer reports are available.

Reprints and permission information is available at http://www.nature.com/reprints

Publisher's note Springer Nature remains neutral with regard to jurisdictional claims in published maps and institutional affiliations.

Open Access This article is licensed under a Creative Commons Attribution 4.0 International License, which permits use, sharing, adaptation, distribution and reproduction in any medium or format, as long as you give appropriate credit to the original author(s) and the source, provide a link to the Creative Commons license, and indicate if changes were made. The images or other third party material in this article are included in the article's Creative Commons license, unless indicated otherwise in a credit line to the material. If material is not included in the article's Creative Commons license and your intended use is not permitted by statutory regulation or exceeds the permitted use, you will need to obtain permission directly from the copyright holder. To view a copy of this license, visit http://creativecommons.org/ licenses/by/4.0/.

(C) The Author(s) 2022 